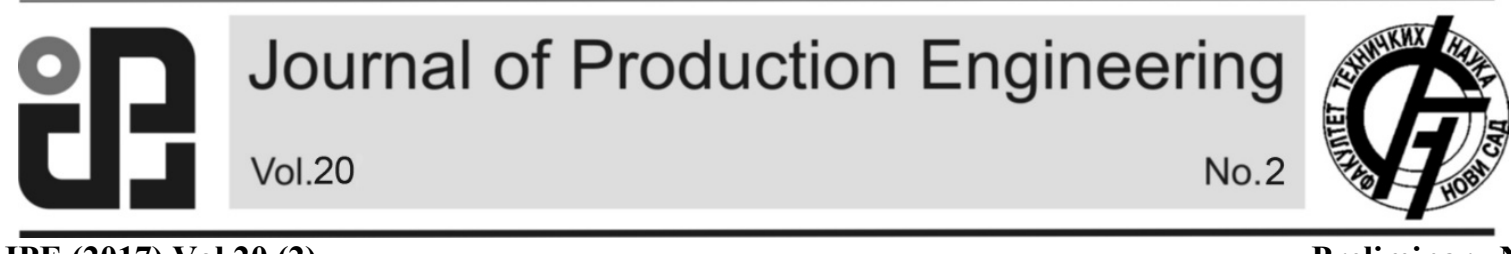

JPE (2017) Vol.20 (2)

Narang, D., Raj, A., Khanna, P.

\title{
MATHEMATICAL MODELLING OF A VIBRATORY BOWL FEEDER FOR SPHERICAL WASHER
}

Received: 09 October 2017 / Accepted: 27 November 2017

Abstract: Mass production has eliminated the craftwork from a majority of industries and brought about a revolutionary change. Automation has evolved along the past years and has become much more sophisticated due to continual starvation for quality. Feeders play a paramount role on the production line. The present study employs a full factorial design technique to analyse the effect of various parameters and interactions between them on output feed rate in a vibratory bowl feeder using spherical washer. An empirical relation followed the analysis of the model. Finally the validation of the model reflected the correctness of the experimental results.

Keyword: Mass Production, Automation, Feeders, Full Factorial design

Matematičko modeliranje vibraciono kuglične hranilace za sferični perač. Masovna proizvodnja eliminisala je zanatsku rad iz većine industrija $i$ dovela do revolucionarne promene. Automatizacija je evoluirala poslednjih godina i postala je mnogo sofisticirana zbog kontinuirane potrašnje za kvalitetom. Hranioci igraju najveću ulogu na proizvodnoj liniji. Ova studija koristi pun faktorni dizajn za analizu uticaja različitih parametara i interakcija između njih na izlaznu brzinu prenosa u vibracionom držaču posuda pomoću sferičnog perača. Empirijska relacija je sledio analizu modela. Konačno, validacija modela odražava ispravnost rezultata eksperimenta.

Ključne reči: Masovna proizvodnja, automatizacija, hranilice, pun faktorni plan

\section{INTRODUCTION}

With the increased demand as well our insatiable thirst for quality has led to the evolution of mass production. Automation is the key ingredient to the success of mass production. On the production line we have different stations, each station responsible for mounting a component on the assembly from the previous station. The parts are to be fed one at a time and it is required to orient them in a particular fashion before mounting onto the assembly. These purposes are quite easily satisfied by feeders. Feeders benefit by saving cost incurred on manual labour, saves time, gives higher production rate and most importantly consistency in quality. There exists a variety of feeders including belt feeders, rotary feeders (drum, table, etc.), centrifugal feeders, vibratory feeders, apron feeders, etc. In this paper, the part feeder of interest is vibratory bowl feeder. Vibratory bowl feeder was patented by Yoshiyuki Hirose [1]. It is the most versatile, robust, reliable and widely used part feeder in the industry. They are generally used for feeding small parts and aligning them. A vibratory bowl feeder generally consists of a bowl (which carries the track via which the part is fed and oriented) and the base. The bowl is mounted onto the base with help of three or four inclined leaf springs. The leaf springs helps to restrict the vibration in the vertical direction. The vibrations are produced with the help of an electromagnet mounted between the base and the bowl. The parts are randomly oriented inside the bowl initially. As the AC supply is turned on the parts, start climbing and moving along the track. The parts are then oriented accordingly by provision of suitable tooling. Each component of tooling either orients the part or pushes it out of the track and hence the same journey of the part begins unless it comes into desired orientation. The base of feeder is provided with a damping material in order to prevent transmission of vibrations to the surroundings. During each vibration cycle the part moves up the track. This upward (slanting) motion can be understood by analysing the motion of bowl and the component. Maul.et al [2] analysed the motion of bowl and the part separately and proposed a model for the same. Lim.et al [3] gave a motion study of the vibratory feeder using turbo $\mathrm{C}++$ language which can be used to determine the position and velocity of the parts at small tie intervals. Though studying the working principle and dynamics of a vibratory feeder is in itself a very engrossing topic and still titillates the minds of researchers, the present paper will be focussing on evolving a model for analysing and optimizing parameters for a certain part being fed to the vibratory bowl feeder.

\section{EXPERIMENTAL SETUP}

Primary steps of the experiment include-1) Identification of the part, 2) Setting up the track for orienting and feeding the part, 3) Defining the independent parameters (inputs) and dependent parameter (output). The part chosen was a spherical washer. The tooling and obstructions on the track were designed according to the orientation of the part required at the end. The tooling in the track and component can be shown as in fig. 1(a) and (b). The orientation was decided by dropping numerous units of washer on a surface and identifying the orientation that 
maximum number of parts adopted. Validation of the drop test has been proved by Ngoi.et al [4]. As far as input variables are concerned, the three controllable variables are-

(i) Size of the part

(ii) Part Population- It is defined as total number of parts present in the bowl at any time.

(iii) Frequency of vibration

The above 3 factors play a crucial role in development of the statistical model using $2^{\mathrm{k}}$ full factorial design. The range for the parameters was to be decided in order to ensure the working of apparatus within controllable limits and hence were finally drawn out after carrying out many pilot runs. The upper and lower limit of each parameter are depicted in Table 1 . Factors like inclination of the spring, coefficient of friction, etc. could not be varied due to mechanical constraints and hence were kept constant for the present experimentation [5].

(a)

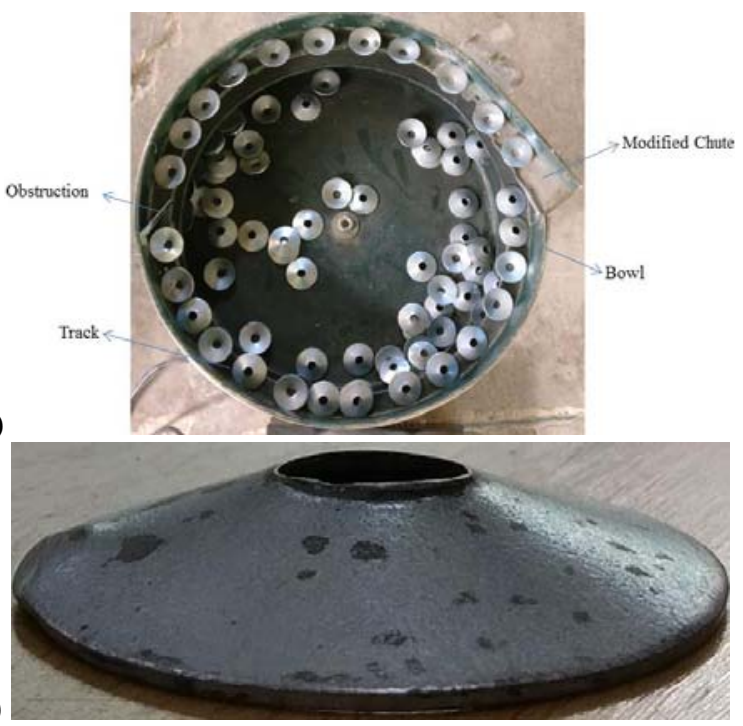

Fig. 1. Track and Component

\begin{tabular}{|c|c|c|}
\hline Factors & $\begin{array}{c}\text { Lower } \\
\text { Limit }\end{array}$ & $\begin{array}{c}\text { Upper } \\
\text { Limit }\end{array}$ \\
\hline $\begin{array}{c}\text { Diameter of the part(in } \\
\text { mm) }\end{array}$ & 15 & 25 \\
\hline Part population & 50 & 200 \\
\hline $\begin{array}{c}\text { Frequency of } \\
\text { vibrations(in Hz) }\end{array}$ & 35 & 50 \\
\hline
\end{tabular}

Table 1. Range of parameters

\begin{tabular}{|c|c|c|c|c|}
\hline $\begin{array}{c}\text { Run } \\
\text { No. }\end{array}$ & $\begin{array}{c}\text { A: } \\
\text { Diameter } \\
\text { of the } \\
\text { part }\end{array}$ & $\begin{array}{c}\text { B: } \\
\text { Part } \\
\text { Population } \\
\text { (PP) }\end{array}$ & $\begin{array}{c}\text { C: } \\
\text { Frequency }\end{array}$ & $\begin{array}{c}\text { D: } \\
\text { Response }\end{array}$ \\
\hline $\mathbf{1}$ & -1 & 1 & 1 & 99 \\
\hline $\mathbf{2}$ & -1 & 1 & -1 & 52 \\
\hline $\mathbf{3}$ & 1 & -1 & -1 & 5 \\
\hline $\mathbf{4}$ & 1 & 1 & 1 & 22 \\
\hline $\mathbf{5}$ & 1 & 1 & -1 & 15 \\
\hline $\mathbf{6}$ & -1 & -1 & -1 & 14 \\
\hline $\mathbf{7}$ & -1 & -1 & 1 & 58 \\
\hline $\mathbf{8}$ & 1 & -1 & 1 & 15 \\
\hline
\end{tabular}

Table 2. Response of the run
Since we have 3 parameters which are to be varied, hence the applicable model is $2^{3}$ factorial design. Thus the model requires 8 runs, each run with a particular combination of the parameters at there extreme values i.e. each factor takes either upper or lower limit. The response for the 8 runs are shown in Table 2 with upper and lower limits coded as (+1) and (-1) respectively.

\section{RESULT AND ANALYSIS OF THE MODEL}

Examination of effect of each factor on the output can easily be understood by obtaining the Cube plot, One Factor plot and Interaction plot. Significance of each factor can be analysed by obtaining the HalfNormal, Normal and Pareto plots. Analysis of Variance (ANOVA) table is obtained which clearly indicates significant factors affecting the feed rate (response).

\subsection{Effect of factors on feed rate}

The Cube plot (in fig. 2) depicts the average feed rate (in units $/ \mathrm{mm}$ ) at the extremities of the input variables. In coded form, it can be further be explained as a plot indicating feed rates when each variable is either at +1 (high) or -1 (low) level, or simply it can be stated that cubic plot represents the average feed rate at the critical points. It can be inferred from the plot that a minimum feed rate of 5.8 (approx. 6) parts per minute can be obtained with maximum part size (25mm) coupled with minimum frequency $(35 \mathrm{~Hz})$ and minimum part population (PP) (50). Similarly maximum feed rate of 98.3 (approx. 99) parts per minute is observed with minimum size $(15 \mathrm{~mm})$, maximum frequency $(50 \mathrm{~Hz})$ and maximum PP (200).

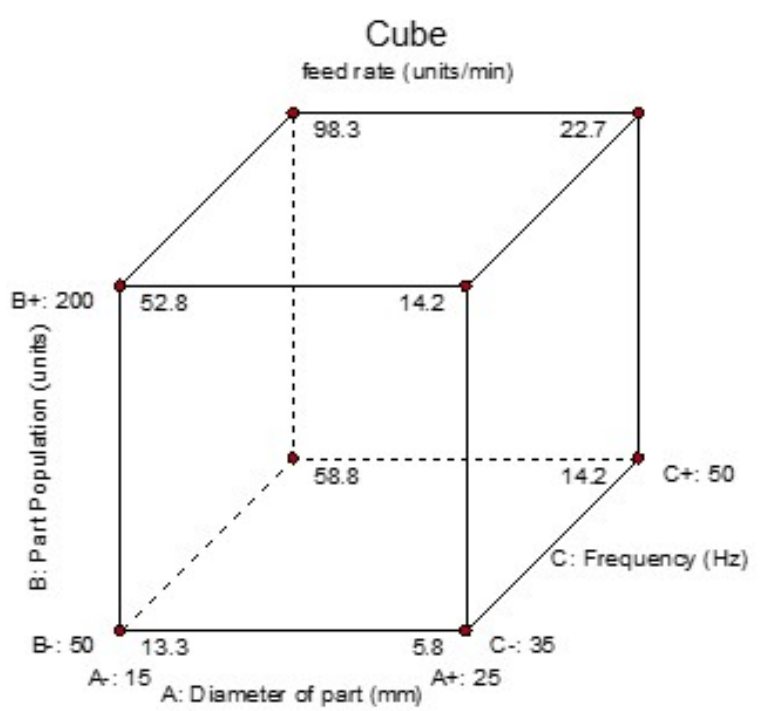

Fig. 2. Cube plot

Fig. 3 shows the feed rate plotted against individual parameters i.e. they give an intimation of how the response would change if only one parameter is varied while the other two are kept constant. These plots are known as one factor plots. The previous study done by authors dealt with graphical analysis based on one factor at a time technique [6]. It can be observed that there exists an inverse relationship between feed 
rate and the part size. This behaviour can be attributed to the fact that with increase in part size the number of parts present on any particular length of the track decreases hence causing a fall in the feed rate. Also feed rate is directly proportional to the part population and the frequency. The increase in PP leads to increase in the no. of parts at any time in the bowl hence increasing the feed rate.
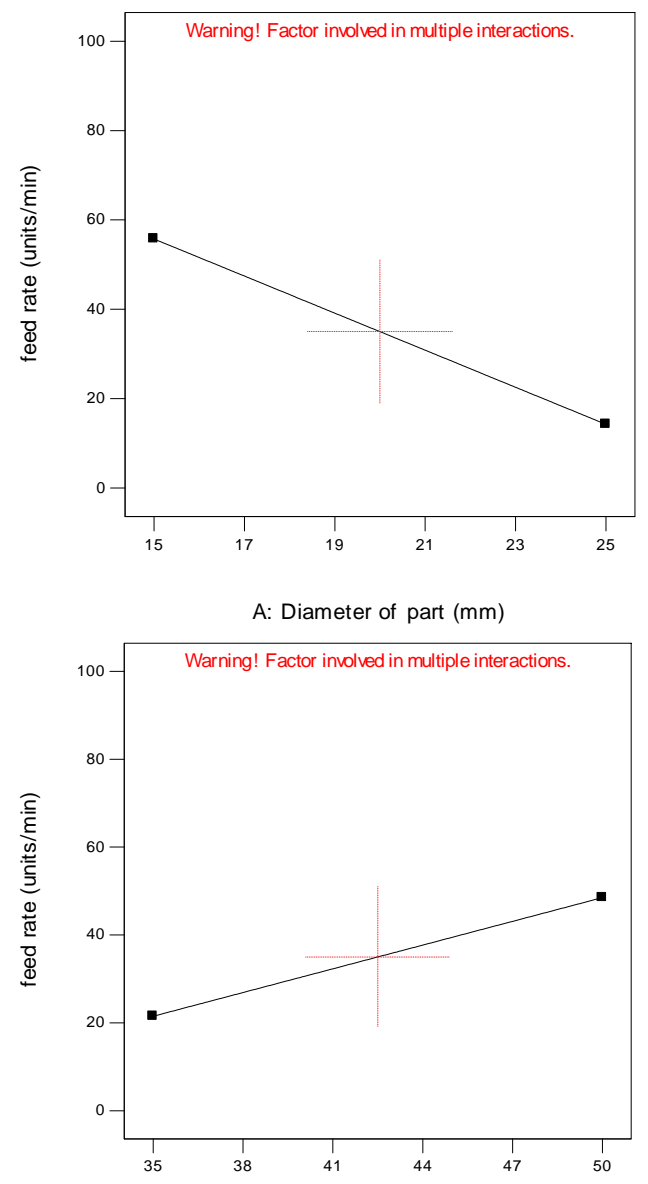

C: Frequency $(\mathrm{Hz})$

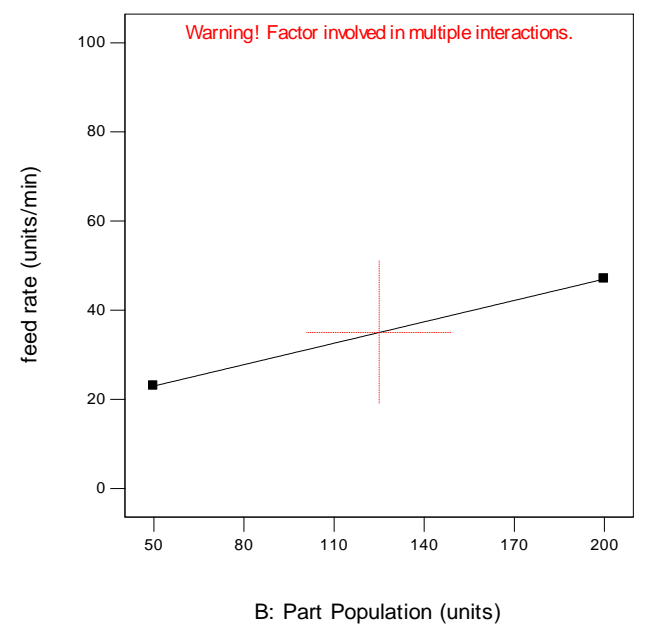

Fig. 3. One Factor plot

Also the increase in frequency gives a greater push or assists in hopping the part to a greater distance. But increase in frequency beyond a limit causes the feed rate to decrease because of collision of parts among themselves. From the slope of the plots, it can firmly be stated that diameter/ size of the part plays a much significant role than the other two. Another type of plot as depicted in fig. 4, 5 and 6 is called the interaction plot. Fig 4, 5 and 6 show the interaction between parameters $\mathrm{AB}, \mathrm{AC}$ and $\mathrm{BC}$ respectively. These plots assist in investigating the effect on feed rate due to change in a particular input factor when that input factor itself is dependent on other inputs. Understanding of a simple statement can fetch us great information about the interaction plots. It can be stated as "greater the deviation of the set of lines from parallelism, more significant will be the interaction between them”. At a constant frequency (C) (fig.4) we have feed rate varying with the diameter of the part (A) for the 2 levels of part population (B). The black line indicates feed rate vs diameter when $\mathrm{PP}=50$, while the red line indicates the same relation when $\mathrm{PP}=200$. Similar observation is made in fig. 5 with the interaction shown between diameter and frequency. In both the figs. 4 and 5 we see that lines are non- parallel and tend towards each other thus showing quite significant interactions. On the other hand, fig. 6 shows interaction between PP and frequency is parallel and hence is of negligible significance.

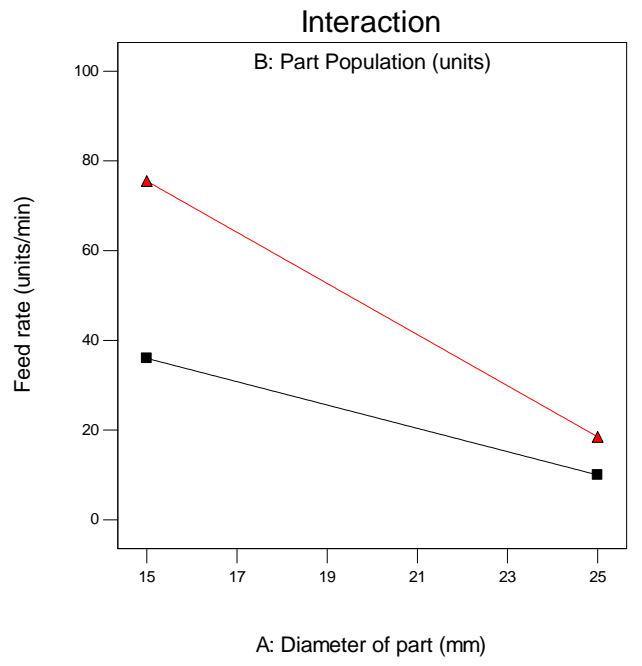

Fig. 4. Interaction plot between diameter (A) and part Population (B)

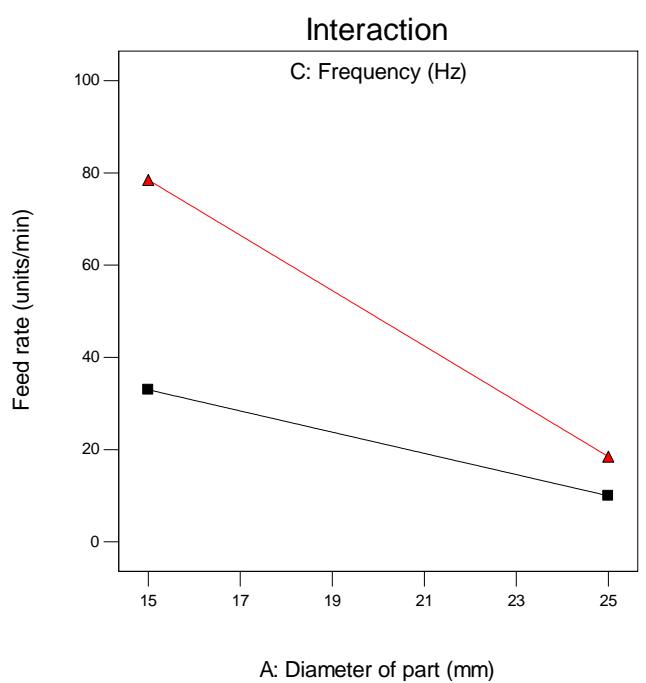

Fig. 5. Interaction plot between diameter (A) and frequency $(\mathrm{C})$ 


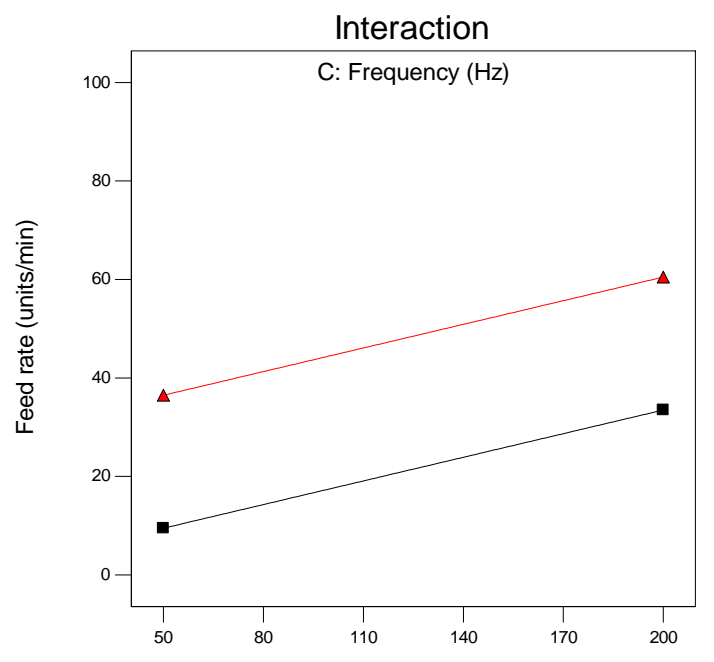

B: Part Population (units)

Fig. 6. Interaction plot between part population (B) and frequency $(\mathrm{C})$

\subsection{Significance of various factors}

The Half-Normal and Pareto plot also indicate the relative significance of each factor or a group of factors. From Half-Normal (fig. 7) plot we infer that farther the point from the line, more is its significance.

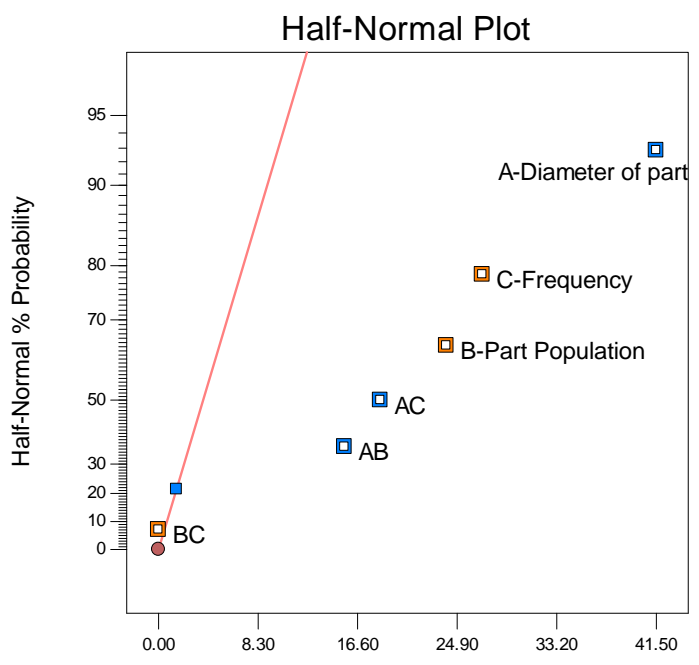

Fig. 7. Half-Normal plot
Thus diagnosis of the two plots gives the sequence of importance of factors as- A, C, B, AC, AB, BC. However we can assume that $A C, A B$ and $B C$ have relatively little importance when compared to $\mathrm{A}, \mathrm{C}$ and B. Pareto chart (as shown in fig. 8) provides us with the absolute effect values. It draws a reference line at tvalue limit. Analysing the chart we draw the same conclusion as from Half-Normal and Normal plots.

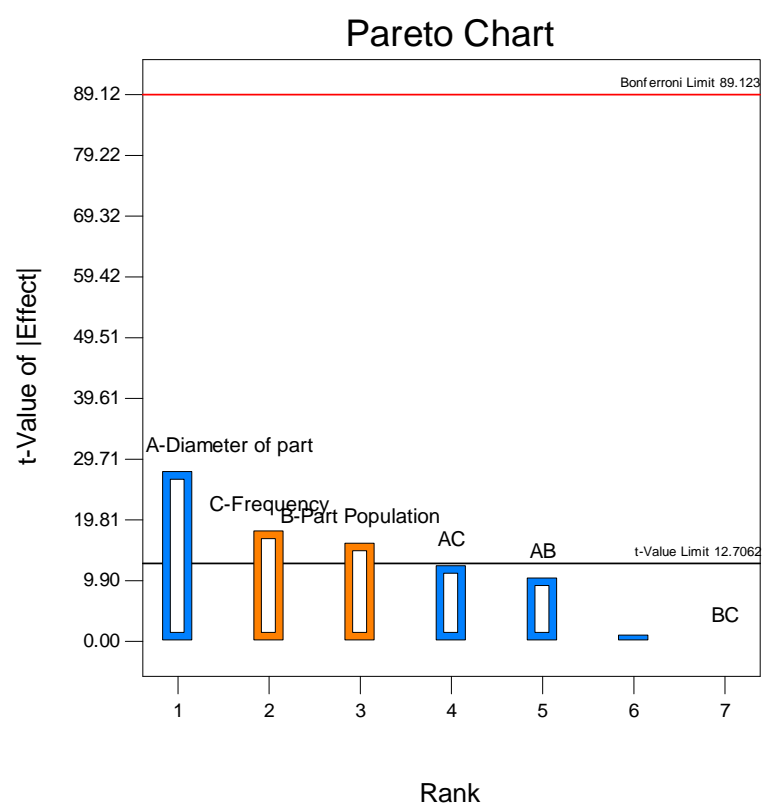

Fig. 8. Pareto chart

As seen from the results in table 3, the terms in the last column (i.e.'Prob $>$ F') having value less than 0.0500 are the significant terms. Hence we get the order of significance as- A, C, B, AC, AB, BC which is same as discussed earlier. The 'F-value' compares the variance of each term with the residual variance. Mean square of a particular term divided by mean square of residual $\mathrm{P}$ equals the ' $\mathrm{F}$-value'. $\mathrm{P}$ is the probability of 'F- value of the term' [7]. A 3D plot as shown in fig. 9 also gives the epitome of the effect of multiple factors on the response by plotting feed rate against multiple parameters, thus generating a coloured and shaped contour. The colour at various points in space give the magnitude of feed rate.

\begin{tabular}{|c|c|c|c|c|c|}
\hline Source & Sum of Squares & Df & Mean Square & F Value & $\begin{array}{c}\text { p-value Prob } \\
\text { > F }\end{array}$ \\
\hline Model & 7219.50 & 6 & 1203.25 & 267.39 & 0.0468 \\
\hline A-Diameter of part & 3444.50 & 1 & 3444.50 & 765.44 & 0.0230 \\
\hline B-Part Population & 1152.00 & 1 & 1152.00 & 256.00 & 0.0397 \\
\hline C-Frequency & 1458.00 & 1 & 1458.00 & 324.00 & 0.0353 \\
\hline AB & 480.50 & 1 & 480.50 & 106.78 & 0.0614 \\
\hline AC & 684.50 & 1 & 684.50 & 152.11 & 0.0515 \\
\hline BC & 0.000 & 1 & 0.000 & 0.000 & 1.0000 \\
\hline Residual & 4.50 & 1 & 4.50 & & \\
\hline Cor Total & 7224.00 & 7 & & & \\
\hline
\end{tabular}

Table 3. ANOVA 


\subsection{Significance of the model}

From the model, we obtained 2 empirical relations. However the term ABC, signifying interaction of all 3 factors is ignored to maintain the hierarchical nature of the model. The 2 formulae obtained are as follows-

(i) In terms of coded factors: It contains the coded value of factors ranging from -1 to +1 and thereafter can be used to determine the feed rate for given level of factors. Relative impact of each factor can be determined by the coefficients of the factors.

$$
\begin{aligned}
& \text { Feed Rate }=35.00-20.75 \times A+12.00 \times B \\
& +13.50 \times C-7.75 \times A \times B-9.25 \times A \times C \\
& +0.000 \times B \times C
\end{aligned}
$$

(ii) In terms of actual factors: It contains factors with there actual values and hence an unknown variable can be found out by putting the value of other known variables. As compared to the coded model, the actual model is less accurate as the terms are rounded off.

$$
\begin{aligned}
& \text { Feed Rate }=-239.83333+8.91667 \times A \\
& +0.57333 \times B+6.73333 \times C \\
& -0.020667 \times A \times B-0.24667 \times A \times C \\
& -2.76336 \times 10^{-17} \times B \times C
\end{aligned}
$$

The information in table 4 is obtained from the test runs. The "Pred R- Squared" of 0.9601 is in agreement with "Adj R-Squared" of 0.9956 since the difference between the two is less than 0.2. "Adeq Precision" is a measure of signal to noise ratio. The "Adeq Precision" of 46.616 signifies an adequate signal. "R-Squared” is a statistic which measures the variability associated with the model. Its value comes out to be 0.9994(99.94\%). Problem with "R- Squared" is that its value increases as factors are added to the model even if the terms are

\begin{tabular}{|c|c|c|c|}
\hline Std. Dev. & 2.12 & R-Squared & 0.9994 \\
\hline Mean & $\begin{array}{c}35.0 \\
0\end{array}$ & Adj R-Squared & 0.9956 \\
\hline C.V. \% & 6.06 & Pred R-Squared & 0.9601 \\
\hline PRESS & $\begin{array}{c}288 . \\
00\end{array}$ & Adeq Precision & 46.616 \\
\hline $\begin{array}{c}-2 \text { Log } \\
\text { Likelihood }\end{array}$ & $\begin{array}{c}18.1 \\
0\end{array}$ & BIC & 32.66 \\
\hline
\end{tabular}
insignificant. "PRESS (Prediction Sum of Error Squares)" is 288.00 and is useful in computing the value of "Pred R-Squared". A plot between actual and predicted values of the model depicted in fig. 10.

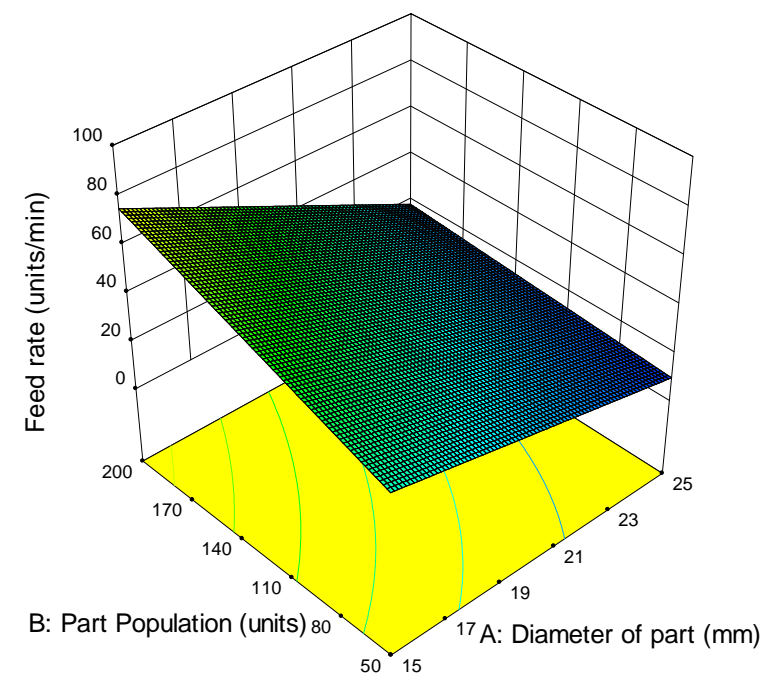

Fig. 10. 3D Surface plot
Table 4. Model Results

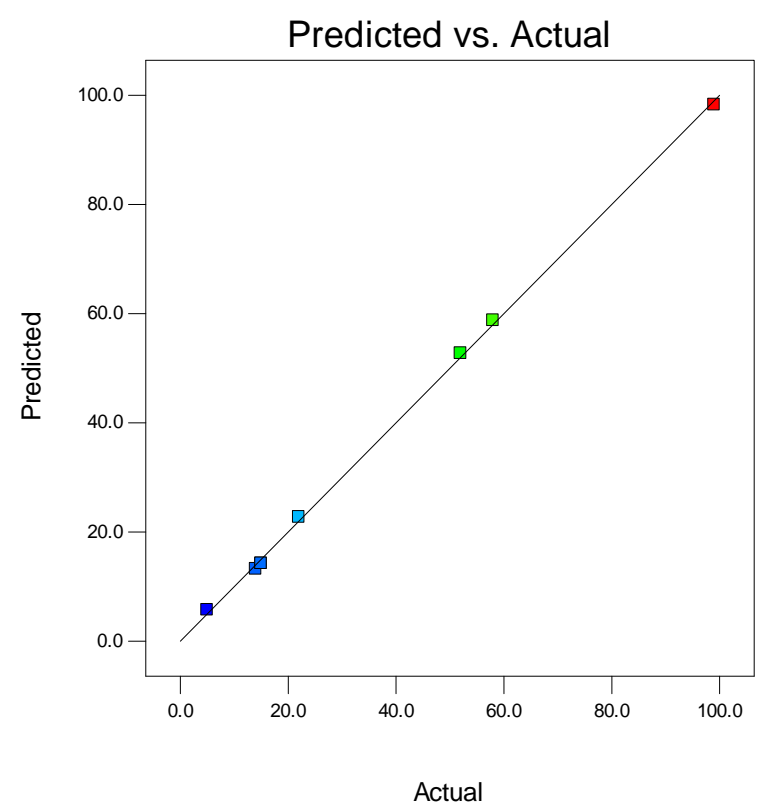

Fig. 11. Predicted vs. Actual plot

\section{VALIDATION OF THE MODEL}

The correctness of the model can be checked by comparing the experimental value (E.V.) and the theoretical values (T.V.) and thereafter calculating the percentage error. T.V. of the feed rate can be calculated from the equation containing factors with there actual values. Formula for percentage error is given as:

$$
\text { Percentage Error }=\frac{(E . V .-T . V .) \times 100}{T . V .}
$$

Table 5 shows the percentage error. By observation of the error values we can state that the values predicted by the model are in accordance with the experimental results.

Average percentage error $=5.984 \%$ Accuracy $=94.016 \%$

\begin{tabular}{|c|c|c|c|}
\hline S. No. & $\begin{array}{c}\text { Calculated/ } \\
\text { Theoretical } \\
\text { Value (T.V.) }\end{array}$ & $\begin{array}{c}\text { Experimental } \\
\text { Value(E.V.) }\end{array}$ & $\begin{array}{c}\text { Percentage } \\
\text { Error }\end{array}$ \\
\hline $\mathbf{1}$ & 86.77 & 90 & 3.72 \\
\hline $\mathbf{2}$ & 73.62 & 77 & 4.59 \\
\hline $\mathbf{3}$ & 44.3 & 49 & 10.6 \\
\hline $\mathbf{4}$ & 29.1 & 30 & 3.09 \\
\hline $\mathbf{5}$ & 87.1 & 94 & 7.92 \\
\hline
\end{tabular}

Table 5. Error in the model 


\section{CONCLUSION}

An efficient and reliable model for optimum feed rate was successfully developed using $2^{3}$ factorial design. The "Pred R-Squared" of 0.9601 indicates variability of $96.01 \%$ in the new data. The effect of individual parameters on feed rate can be concluded as: 1. The feed rate decreases with increase in size of the part.

2. The feed rate increases with increase in part population.

3. The feed rate increases with increase in frequency up to a particular level.

The model developed not only predicts the effect on output due to individual factors but also due to the interactions between the parameters. Validation of the model indicates an accuracy of $94.016 \%$ which signifies that results are in accordance with the model.

\section{REFERENCES}

[1] Phillips I T S, Costa K D, I R, Chambers T V and Hill R 1994 United States Patent [19]

[2] Maul G P and Brian Thomas M: A systems model and simulation of the vibratory bowl feeder J. Manuf. Syst. 16 309-14, 1997

[3] Lim G H: Vibratory feeder motion study using Turbo $C++$ language Adv. Eng. Softw. 18 53-9,
1993

[4] Ngoi B K ., Lim L E . and Ee J T: Analysis of Natural Resting Aspects of Parts in a Vibratory Bowl Feeder - Validation of "Drop Test" Int. J. Adv. Manuf. Technol. 300-10, 1997

[5] Kukreja A, Chopra P, Aggarwal A and Khanna P: Application of Full Factorial Design for Optimization of Feed Rate of Stationary Hook Hopper Int. J. Model. Optim. 1 205-9, 2011

[6] Raj A, Narang D and Khanna P: Graphical Analysis of a Vibratory Bowl Feeder for spherical washer Journal of Material Science and Mechanical Engineering 4 110-3, 2017

[7] Chauhan A: Mathematical Analysis of U Shaped Components Feeding in a Vibratory Bowl Feeder International Journal of Electronics, Electrical and Computational System 5 91-9, 2016

Authors: Research Scholar Daksh Narang, Research Scholar Ayush Raj, Associate Professor Pradeep Khanna, Division of Manufacturing Processes and Automation Engineering, Netaji Subas Institute of Technology, University of Delhi, New Delhi-110078, India, Phone: +91 9891043115.

E-mail: daksh_narang@yahoo.com ayushr1995@gmail.com 4.khanna@gmail.com 